\title{
Ayurvedic Enema Therapy in the Management of Thromboangitis Obliterans (TAO) - A Case Study
}

\author{
Madan Bhandari ${ }^{1}$, Prasanna N Rao ${ }^{1}$, Suhas Kumar Shetty ${ }^{1}$ and Gopikrishna BJ ${ }^{2}$ \\ ${ }^{1}$ Department of Shalya Tantra, Sri Dharmasthala Manjunatheshwara College of Ayurveda and Hospital, Hassan, Karnataka \\ ${ }^{2}$ Research and Development Unit, Sri Dharmasthala Manjunatheshwara College of Ayurveda and Hospital, Hassan, Karnataka
}

* Corresponding author: Madan Bhandari, PG Scholar, Department of Shalya Tantra, Sri Dharmasthala Manjunatheshwara College of Ayurveda and Hospital, Hassan, Karnataka-573201, India, Tel: +0820 253 3302; E-mail: madanbhandari750@gmail.com

Received: June 12, 2018; Accepted: June 26, 2018; Published: June 28, 2018

Citation: Bhandari M, Rao PN, Shetty SK, Gopikrishna BJ (2018) Ayurvedic Enema Therapy in the Management of Thromboangitis Obliterans (TAO) - A case Study. Med Case Rep Vol.4 No.3:75.

\section{Abstract}

Thromboangitis Obliterans (TAO) is a non-atherosclerotic inflammatory disorder of unknown etiology that affects small and medium-sized vessels of the extremities and has a strong association with smoking.

The clinical criteria include: age under 45 years; current or recent history of tobacco use; presence of distal-extremity ischemia indicated by claudication, pain at rest, ischemic ulcers or gangrenes and documented by non-invasive vascular testing.

A diagnosed case of TAO with gangrene on right great toe with post lumbar sympathectomy status was admitted for severe pain on right lower limb.

Ayurvedic Enema therapy (Manjisthadi Kshara Basti) for 30 days (Karma Basti) was given for the patient who resulted in significant clinical improvement on the pain and subsequent healing of ulcer.

Oil based enema made up Rubia cordifolia and other ingredients (Manjisthadi Taila) and Alkali Based Enema therapy (Kshara Basti) mixed with Manjishthadi Kwatha (decoction of Rubia cordifolia and other ingredients) was executed here on alternate days and has shown significant results on the pain, claudication distance etc.

Keywords: Thromboangitis Obliterans; Manjisthadi Kshara Basti; Karma Basti; Anubhuta Yoga

\section{Introduction}

Thromboangitis Obliterans (TAO), an inflammatory vasculopathy also known as Buerger's disease, is same variety of disease where inflammatory endarteritis hampers the proper blood supply.
The condition has strong association with tobacco use [1]. The onset of Buerger's disease occurs between 40 and 45 years of age, and men are most commonly affected.

It begins with ischemia of the distal small vessels of the arms, legs, hands and feet. Involvement of the large arteries is unusual and rarely occurs in the absence of occlusive disease of the small vessels [2].

In Modern medicine, Analgesics, vasodilators, Anti-platelet aggregators are some choice for conservative management [3].

Lumbar Sympathectomy provides short-term pain relief and promotes ulcer healing in patients with Buerger's disease but carries no long-term benefit [4].

The symptoms of TAO can be well correlated with Gambhira Vatarakta [5] in Ayurveda. Alkaline Enema (Kshara Basti) [6] is explained by Chakradatta and Decoction of Rubia cordifolia.

Other ingredients (Manjisthadi Kvath) [7] is explained by Sarangadhara. Alkaline enema of Rubia Cordifolia and other ingredients (Manjisthadi kshara Basti) is an Anubhuta Yoga (established through empirical use) and is effective in management of Srotavarodha (blocked channels).

Based on the above-mentioned views Manjisthadi Kshara Basti was considered for a case of Thromboangitis Obliterans (TAO).

\section{Case Study}

A male patient of age 29 years, a coolie by occupation, from Hassan, Karnataka came to an Ayurveda Hospital with the complaint of pain and burning sensation on right lower limb for 4 months associated with an ulcer on right great toe with complete loss of nail bed for 3 months.

\section{History of present illness}

According to the patient he was apparently healthy 4 months back then he gradually developed pain on right calf region. The pain was cramp like, moderate to severe in 
intensity, initially intermittent in nature and aggravated on exposure to cold and physical activity.

Gradually, he developed swelling and reddish discoloration on right great toe associated with blackish discoloration on fore foot. After a week, there was a crack on right toe and the nail was completely peeled off at night leaving an ulcer (Figure 1).

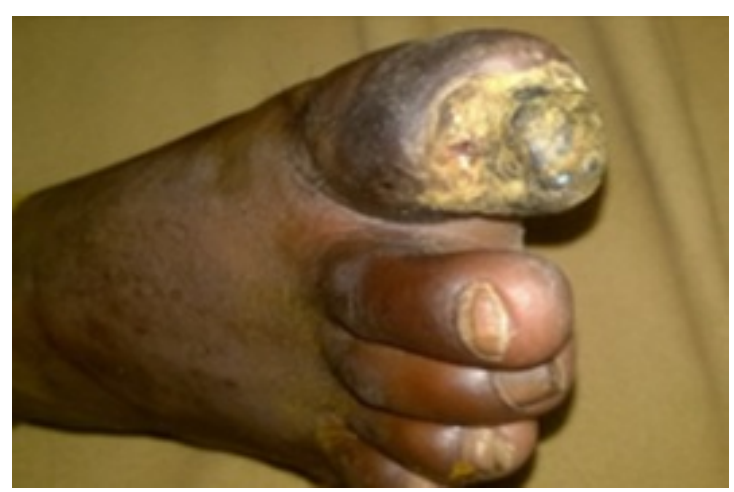

Figure 1 Crack on right toe and the nail was completely peeled off at night leaving an ulcer.

\section{History of past illness}

No history of hypertension, diabetes mellitus, pulmonary tuberculosis.

\section{Treatment history}

For the aforementioned complaints, he visited nearby Medical College where a General Surgeon diagnosed him of Thromboangitis Obliterans (TAO) on Right Lower Limb and advised anti-platelet aggregators and analgesics. As the pain and ulcer was not reduced with the medicines he re-visited the hospital after 2 weeks of treatment. Then he was adviced for Right Lumbar Sympathectomy and the operation was done.

After Lumbar Sympathectomy, blackish discolouration on the fore foot got reduced but the pain and ulcer remained the same. Later, he was referred to Vascular Surgeon at Bangalore.

At Bangalore, the Vascular Surgeon added some medications and counselled him to be prepared for Below Knee Amputation if the condition remains the same.

The patient continuously took the medicines for 2 weeks but the pain was not desirably subsided.

As, the patient was not ready for Amputation he left the follow-up and came for consultation in our hospital.

\section{Personal history}

Appetite - Decreased,

Bowel - Regular,

Micturition - Normal,

Sleep - Disturbed due to pain.
Habits: Chronic smoker for 9 years, 1 pack per day (25 cigarettes per pack), Mixed beedi and cigarette.

\section{Examination of patient}

Blood pressure $-130 / 80 \mathrm{mmHg}$ on supine position, Pulse 76 bpm, regular.

Pallor-Icterus-Lymphadenopathy-Cyanosis-ClubbingOedema-Dehydration: Not present.

Respiratory system: Bilateral equal air entry, Normal vesicular breath sounds present.

Abdomen: Soft, non-tender, no organomegaly.

Cardiovascular system: S1-S2 sound heard, No murmurs.

Central nervous system: Oriented to time, place and person.

\section{Local examination}

Inspection: An ulcer on right great toe, dry and hard on consistency with nail bed peeled off, loss of hairs

Palpation: Right lower limb-Decreased local temperature, popliteal artery, Posterior Tibial Artery, Anterior tibial artery, Dorsalis pedis artery not palpable.

Gait: Limping gait with intermittent claudication, claudication distance-30 metres (Figure 2).

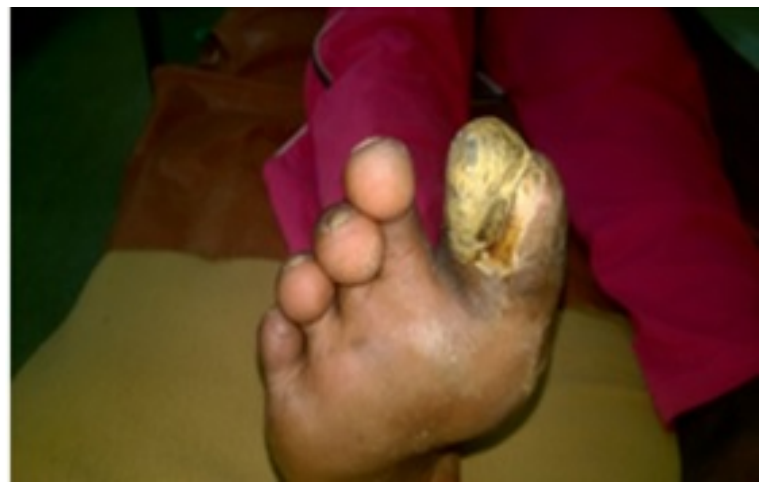

Figure 2 Limping gait with intermittent claudication.

Investigations: Arterial Doppler of Right Lower Limb: Near complete stenosis ( $190 \%$ ) of distal popliteal artery causing significant reduced flow in posterior tibial artery and distal popliteal artery.

\section{Diagnosis}

Thromboangitis Obliterans (TAO) with dry gangrene on right great toe/ $s / p$ right lumbar sympathectomy

\section{Treatment}

The patient was advised for Ayurvedic Enema for 30 days (Karma Basti) with alternate day only medicated oil enema (Anuvasana Basti of Manjisthadi Taila) and medicinal decoction 
enema (Niruha Basti) of Manjisthadi Kwatha and other ingredients listed below (Table 1).

Table 1 Ayurvedic enema for 30 days with alternate day only medicated oil enema and medicinal decoction enema of Manjisthadi Kwatha and other ingredients.

\begin{tabular}{|l|l|l|}
\hline Ingredients & Latin/English name & Amount \\
\hline Saindhava Lavana & Rock Salt & $5 \mathrm{~g}$ \\
\hline Manjisthadi Taila & $\begin{array}{l}\text { Oil of Rubia cordifolia and } \\
\text { Other ingredients }\end{array}$ & $60 \mathrm{ml}$ \\
\hline Madhu & Honey & $80 \mathrm{ml}$ \\
\hline Manjisthadi Kwath & $\begin{array}{l}\text { Decoction of Rubia } \\
\text { cordifolia and other } \\
\text { ingredients }\end{array}$ & $100 \mathrm{ml}$ \\
\hline Gomutra & Cow's urine & $100 \mathrm{ml}$ \\
\hline Kanji & Medicinal rice gruel & $100 \mathrm{ml}$ \\
\hline
\end{tabular}

Dressing with Jatyadi taila (Herbal oil, where jasmine is chief ingredient) on the ulcer once daily (Table 2).

Table 2 Observations of the treated patient.

\begin{tabular}{|l|l|l|}
\hline Parameters & Before Treatment & After Treatment \\
\hline $\begin{array}{l}\text { Pain and Burning sensation } \\
\text { on Right lower limb }\end{array}$ & $\begin{array}{l}\text { Visual Analogue } \\
\text { Scale- 8 points }\end{array}$ & $\begin{array}{l}\text { Visual Analogue } \\
\text { Scale-3 points }\end{array}$ \\
\hline Claudication distance & 30 metres & 500 metres \\
\hline Ulcer & $\begin{array}{l}\text { Purulent discharge } \\
\text { present }\end{array}$ & Healed \\
\hline Skin Discolouration & $\begin{array}{l}\text { Present on the right } \\
\text { fore foot }\end{array}$ & Reduced \\
\hline Sleep & $\begin{array}{l}\text { Disturbed due to } \\
\text { severe pain }\end{array}$ & Sound Sleep \\
\hline Size of ulcer & $\begin{array}{l}3 \times 1 \times 0.5 \mathrm{~cm} \text { with } \\
\text { purulent discharge }\end{array}$ & Healed completely \\
\hline
\end{tabular}

\section{Discussion}

TAO is one of the most painful vascular disease. The longterm management of it is challenging for the modern surgeons too. In the aforementioned case the patient consulted various General Surgeons and Vascular Surgeons and continuously took the medications that were prescribed for him. He was advised for Right Lumbar Sympathectomy and was operated which was even unable to relieve the pain of patient.

The sign and symptoms of TAO can be well correlated with Gambhira Vatarakta in Ayurveda. In Vatarakta, due to the diet and lifestyle aggravating the Rakta (blood), the Rakta gets vitiated and it does the Avarana (covering) of Vata. Vata Prakopa (aggravation) happens and it gets localized on different parts of the body manifesting the signs and symptoms of aggravated Vata like pain etc. In Ayurveda, Manjistha (Rubia cordifolia) is a renowned Rakta Prasadaka (Blood purifier), Tridoshahara (balancing the 3 Doshas) and Srotosodhaka (cleansing the channels). So, use of Manjisthadi Kvath (decoction) and Manjisthadi Taila (oil) purifies the Rakta (blood), pacifies the Vata and makes the proper flow inside the channels (Srotosodhaka). Kshara Basti (Alkaline Enema) has the fast spreading activity which helps to clean the peripheral vascular channels. Hence, the combination Basti is very effective on Peripheral Vascular Diseases like TAO.

\section{Conclusion}

Thromboangitis obliterans (TAO) is a painful disease of mainly medium sized blood vessels. It is progressive and associated with severe pain according to ischaemic changes. It is directly associated with tobacco smoking.

An endeavour was made to manage a case of TAO with Ayurvedic treatment which was previously advised for Below Knee Ampuation. The symptoms of TAO can be well correlated with Gambhira Vatarakta in Ayurveda. Ayurvedic Enema (Manjisthadi Kshara Basti) is an Anubhuta Yoga (established by empirical use) showing promising results in TAO. Alkaline Enema (Kshara Basti) is mentioned by Chakradatta and Decoction of Rubia cordifolia (Manjisthadi Kvath) is mentioned by Sarangadhara. Rubia cordifolia (Manjistha) is renowned blood purifier (Rakta Sodhaka), channel cleansing (Srotosodhaka) and the Alkaline Enema (Kshara Basti) removes the Avarana of Vata (Blocking activity of Vata). Hence, TAO can be successfully managed by Ayurvedic Enema therapy (Manjisthadi Kshara Basti).

\section{References}

1. Papa MZ, Adar RA (1992) Critical look at thromboangiitis obliterans (Buerger's disease). Vasc Surg 5: 1-18.

2. Shionoya S, Ban I, Nakata Y, Matsubara J, Hirai M, et al. (1978) Involvement of the iliac artery in Buerger's disease (pathogenesis and arterial reconstruction). J Cardiovasc Surg (Torino) 19: 69-76

3. Brunicardi FC (1969) Schwartz's principles of surgery, (10th edn) McGraw- Hill Companies, Inc, Canada.

4. Lau H, Cheng SW (1997) Buerger's disease in Hong Kong: A review of 89 cases. Aust NZ J Surg 67: 264-269.

5. Samhita AC, Trikamji AY, Sansthan CS (2007) Charaka samhitha with Ayurveda Dipika commentary of Chakrapanidatta, Chikitsasthana, Chaukambha Prakashan, India.

6. http://shodhganga.inflibnet.ac.in/bitstream/ 10603/5959/15/15_bibliography.pdf

7. http://shodhganga.inflibnet.ac.in/bitstream/ 10603/125274/16/16_bibliography\%20references.pdf 